\title{
Tingkat Pengetahuan Perawat Dan Penerapan Ventilator Associated Pneumonia Bundle Di Ruang Perawatan Intensif
}

\author{
Sri Idawati ${ }^{a}$, Emil Huriani $^{\mathbf{a}^{*}}$, Reni Prima Gusty ${ }^{\mathrm{a}}$ \\ ${ }^{\text {a,b,c }}$ Fakultas Keperawatan Universitas Andalas, Kampus Unand Limau Manis, Padang, 25163, \\ Indonesia \\ e-mail korespondensi: emilhuriani@gmail.com
}

\begin{abstract}
According to the Quality and Performance Report Benefits for Society Committee on Prevention and Control of Hospital Infection in 2014 found numerical Infections Ventilator Associated Pneumonia (VAP) 18.17 \%, and in the last six months there were as many as $85.1 \%$ of patients in the ICU who use mechanical ventilation. Available protocol were not in accordance with the VAP bundle. Nurse was inconsistent in applying nursing intervention for VAP prevention. Research objective was to investigate orcrelation of knowledge of healthworkers with application of VAP prevention in ICU Hospital Dr. M. Djamil Padang. The research design was a descriptive cross sectional with total sample of 33 respondents. Analysis of the data by univariate and bivariate analysis. The results showed that $60 \%$ of healthworkers had a high level of knowledge and $93.3 \%$ of healthworkers performance in accordance with application of VAP Bundle. There was a significant relationship between knowledge level and the application of VAP Bundle in ICU $(p=0.001)$. Based on the research, suggested that the hospital is expected to provide variation or special training of nursing dissemination journal critical especially action mechanical ventilation so that the nurses can add insight into the latest knowledge of science so as to increase the quality of nurses. For management of room in order to establish SOP VAP Bundle to be always applied by the nurses in preventing the incidence of VAP.
\end{abstract}

Keyword

: Knowledge, Nurses, Aplication of VAP Bundle

\begin{abstract}
Abstrak
Menurut Laporan Kinerja Mutu dan Manfaat Bagi Masyarakat Komite Pencegahan dan Pengendalian Infeksi Rumah Sakit (PPIRS) pada tahun 2014 ditemukan angka Infeksi Ventilator Associated Pneumonia (VAP) $18,17 \%$, dan dalam enam bulan terakhir terdapat sebanyak $85,1 \%$ pasien di ICU yang menggunakan Ventilasi Mekanik (ventilator). Protap yang tersedia belum sesuai dengan VAP bundle. Ditemukan perawat yang tidak konsisten dalam menerapkan intervensi keperawatan untuk pencegahan VAP dan ketidaktahuan perawat dalam penerapan VAP Bundle. Penelitian ini bertujuan untuk mengetahui hubungan tingkat pengetahuan tenaga kesehatan dengan Penerapan VAP Bundle di ICU RSUP Dr. M. Djamil Padang. Desain penelitian ini adalah analitik dengan pendekatan cross sectional. Data diolah secara deskriptif dan dengan menggunakan chi-squared test. Hasil penelitian menunjukkan bahwa lebih dari separuh (60\%) perawat memiliki tingkat pengetahuan yang tinggi. Hampir seluruh $(93,3 \%)$ perawat sesuai melakukan penerapan VAP Bundle. Terdapat hubungan yang bermakna antara tingkat pengetahuan dengan penerapan VAP Bundle $(\mathrm{p}<0.05)$. Disarankan kepada pihak rumah sakit dapat memberikan variasi pelatihan lanjut atau khusus tentang keperawatan kritis termasuk desiminasi jurnal terutama tindakan ventilasi mekanik sehingga perawat dapat menambah wawasan pengetahuan ilmu-ilmu terbaru sehingga dapat menambah kualitas perawat. Bagi manajemen ruangan agar dapat menetapkan VAP Bundle sebagai prosedur operasional standar sehingga diterapkan secara konsisten oleh para perawat dalam mencegahnya VAP.
\end{abstract}

Kata Kunci : Pengetahuan, Perawat, Penerapan VAP Bundle

\section{PENDAHULUAN}

Ventilasi mekanik (ventilator) memegang peranan penting bagi dunia keperawatan kritis, dimana perannya sebagai pengganti bagi fungsi ventilasi bagi pasien dengan gangguan fungsi respiratorik (Sundana, 2014). Ventilator merupakan alat bantu pernafasan bertekanan negatif atau positif yang menghasilkan udara terkontrol pada jalan nafas sehingga pasien mampu mempertahankan ventilasi dan pemberian oksigen dalam jangka waktu lama. Dimana tujuan dari pemasangan ventilator tersebut adalah mempertahankan ventilasi alveolar secara optimal untuk memenuhi kebutuhan metabolik pasien, memperbaiki hipoksemia, dan memaksimalkan transport oksigen.

Dua cara dalam menggunakan ventilasi mekanik yaitu secara invasif dan 
non invasif. Pemakaian secara invasif dengan menggunakan pipa Endo Tracheal Tube (ETT) yang pemasangannya melalui intubasi, dimana pemasangan pada pipa ETT akan menekan sistem pertahanan host, menyebabkan trauma dan inflamasi lokal, sehingga meningkatkan kemungkinan aspirasi patogen nasokomial dari oropharing disekitar cuff (Setiadi \& Soemantri, 2009). Pemakaian secara non invasif dengan menggunakan masker, penggunaan ventilator non invasif ini di ICU jarang ditemukan, karena tidak adekuatya oksigen yang masuk kedalam paru-paru, kecenderungan oksigen masuk kedalam abdomen, maka dari itu pemakaian ventilator non invasif jarang sekali digunakan (Sherina \& RSCM, 2010).

Ventilator Associated Pneumonia (VAP) adalah jenis infeksi paru-paru yang terjadi pada orang-orang yang terpasang mesin pernafasan (ventilator) dirumah sakit selama lebih dari 48 jam.VAP adalah infeksi yang biasa ditemui dalam situasi perawatan kritis.Prevalensi sebelumnya dan studi kohort prosfektif telah menunjukan bahwa VAP dikaitkan dengan angka morbiditas dan mortalitas yang tinggi berkepanjangan di ICU serta yang tinggal dirumah sakit (Jansson, Kokko, Ylipalosaari, Syarjala, \& Kyngas, 2013).Angka kejadian VAP dilaporkan terjadi $9-27 \%$ dari semua pasien yang terintubasi (Mohamed, 2014).Tingkat keseluruhan Ventilator Associated Pneumonia (VAP) adalah 13,6 per 1.000 ventilator sesuai dengan International Nasocomial Infection Control Consortium (INICC).

Ringkasan laporan data untuk 20032008 dibandingkan dengan 3,3 per 1.000 ventilator hari di US National Healthcare Safety Network (NHSN; sebelumnya National Nasocomial Infection Surveillance System (NNIS)). Pentingnya masalah ini tercermin pada tingginya insiden dan membuat VAP antara infeksi yang paling umum di ICU dan pengobatan dengan biaya tinggi, dengan jumlah hari rawat yang lebih besardi ICU, durasi yang lebih lama dari ventilasi mekanis, dan kematian lebih tinggi (Mohamed, 2014).

Pencegahan yang dapat dilakukan untuk mengatasi VAP adalah dengan VAP Bundle. VAP bundel digambarkan sebagai sekelompok intervensi berbasis-bukti yang akan membantu mencegah VAP. Pentingnya Bundle dalam pencegahan infeksi nasokomial VAP dapat mengurangi biaya 10 kali lipat dan meningkatkan hasil pasien terkait dan keselamatan pasien dan kualitas pelayanan. Intervensi keperawatan kritis dilakukan secara rutin telah terbukti mengurangi angka kejadian VAP. (The Institute for Healthcare Improvement, 2006). The Centers for Disease Control and Prevention (CDC, 2003) dan An European Care Bundle (Rello et al., 2010) telah merancang VAP bundle untuk membantu mengurangi atau menghilangkan VAP dan mempromosikan kepatuhan terhadap pedoman bukti dasar, dalam rangka meningkatkan hasil pasien. Tindakan yang dilakukan seperti elevasi kepala tempat tidur (HOB) $30^{0}-45^{0}$, sedasi harian, Deep Vein Trombosis (DVT) prophylaxis, ulkus peptikum prophylaxis, perawatan mulut (oral care).

Dengan seringnya intervensi keperawatan yang dilakukan oleh petugas yang merawat, berakibat terjadinya penyebaran organisme dari klien ke klien lainnya. Infeksi silang bisa disebabkan oleh perawat, dokter dan staf lainnya yang menjadi medium utama peyebaran infeksi nasokomomial.Tingginya angka infeksi nasokomial ini tidak terlepas dari peranan tenaga kesehatan terutama tenaga keperawatan sebagai tenaga mayoritas di rumah sakit (Saanin, 2006). Perawat yang bekerja pada area critical care harus ditunjang dengan kemampuan, perawat yang professional, berpengalaman, serta mampu mengunakan peralatan modern khususnya ventilasi mekanik (Dewi \& dkk, 2014). Tindakan perawatan ventilasi mekanik merupakan salah satu aspek kegiatan perawat dalam memberikan asuhan keperawatan sehari-hari dalam fungsi independen dan interdenpenden dengan tim medis. 
Menurut penelitian di Filandia tahun 2013, pengetahuan perawat perawatan kritis tentang kepatuhan terhadap pedoman bukti dasar (EBGs/Evidence-based guidelines), untuk mencegah VAP saat ini terbatas.Kurangnya pengetahuan mungkin menjadi penghalang terhadap kepatuhan EBGs.Meskipun seringnya pengingat dan pendidikan tambahan, kepatuhan dan sikap terhadap EBGs dilaporkan miskin (Jansson, Kokko, Ylipalosaari, Syarjala, \& Kyngas, 2013).

Penelitian di Amerika tahun 2012 menegaskan, pendidikan akan meningkatkan hasil pada pasien yang memerlukan ventilasi mekanik, dan pendidikan lanjutan sangat penting untuk perawat yang berkualitas. Dokter dengan gelar Doktor dari praktek keperawatan sangat berperan aktif dalam memfasilitasi kompetensi untuk perawat dalam masalah kesehatan berkualitas, dan harus mengembangkan strategi untuk melaksanakan pedoman VAP dan memperluas basis pengetahuan mereka dengan memberdayakan profesi keperawatan untuk mengobati bukti-dasar pengurangan kejadian VAP.Disamping itu, perawat harus memiliki tanggung jawab untuk memahami penyebab VAP (Gallagher, 2012).

Menurut (Notoadmojo, 2012) perilaku seseorang terbentuk dari pengetahuan, sikap dan tindakan yang saling mempengaruhi satu sama lain, dimana pengetahuan merupakan syarat penting untuk terbentuknya tindakan seseorang. Dengan kata lain, pengetahuan perawat sangatlah penting dalam melakukan perawatan ventilasi mekanik yang berpengaruh terhadap perilaku perawat dalam melakukan penerapan tindakan ventilasi mekanik yang baik. RSUP Dr. M. Djamil Padang adalah rumah sakit rujukan sumatera bagian tengah, yang mana rumah sakit tersebut difasilitasi oleh ruang rawatan, perlengkapan dan tenaga-tenaga SDM yang terlatih. Intensive Care Unit (ICU) adalah ruang rawatan yang ada di RSUP Dr. M. Djamil Padang yang dilengkapi dengan perlengkapan khusus dan staff yang khusus.
Pada survey pendahuluan peneliti melakukan wawancara pada Pengelola Perawatan (PP) ICU pada tanggal 22 Juni 2015 menemukan tenaga di ruangan ICU adalah sebanyak 33 orang, dengan kapasitas 7 kapsitas tempat tidur. SK sebelumnya pada tahun 2007-2014 kapasitas ICU 10 tempat tidur, pada saat inifasilitas yang ada di ICU hanya bisa untuk 7 kapasitas tempat tidur. BORICU pada saat ini (Juni 2015) adalah 69,7\%, dan menurut standar Menkes BOR yang bagus $>100 \%$. Standar Menkes 2005 60\% - 85\%, artinya BOR ICU di RSUP Dr. M. Djamil Padang sesuai dengan Standar Menkes.

Tenaga perawat instalasi rawat intensif RSUP Dr. M. Djamil Padang memiliki 32 orang tenaga keperawatan dengan tingkat pendidikan yang berbeda, yakni S2 keperawatan 1 orang, S1 keperawatan 8 orang, D III keperawatan 28 orang. Semua telah mendapatkan pelatihan dasar dan sebanyak 15 orang yang telah mengikuti pelatihan khusus (pelatihan dasar ventilasi mekanik) (Ruang Rawat Intensif M Djamil Padang, 2015).

Tetapi Di ruang rawat Intensif RSUP Dr. M. Djamil Padang ditemukan adanya angka kejadian VAP yang merupakan infeksi paling tinggi di ICU.Menurut Laporan Kinerja Mutu dan Manfaat Bagi Masyarakat Komite Pencegahan dan Pengendalian Infeksi Rumah Sakit (PPIRS) pada tahun 2014 masih ditemukan angka Infeksi Ventilator Associated Pneumonia (VAP) sekitar $18.17 \%$, dan dalam enam bulan terakhir terdapat sebanyak $85,1 \%$ pasien di ICU yang menggunakan Ventilasi Mekanik (ventilator).

Dengan tingkat pengetahuan yang tinggi, up date info terbaru (seperti adanya pelatihan-pelatihan), berbagai sharing ilmu dengan dokter-dokter yang stase di ICU dan dukungan dari multidisiplin akan menghasilkan intervensi keperawatan kritis yang baik. Seharusnya penerapan VAP Bundle akan terlaksana dengan baik.

Dari observasi yang peneliti lakukan dari 33 perawat ditemukan 10 perawat yang tidak konsisten menerapkan elevasi 
tempat tidur $30^{\circ}-40^{\circ}, 15$ perawat yang tidak secara konsisten menerapkan DVT prophylaxis, 5 perawat yang tidak secara konsisten menerapkan ulkus peptikum prophylaxis, 5 perawat yang tidak konsisten menerapkan mencuci tangan sebelum melakukan tindakan, dan 10 perawat yang tidak konsisten menurunkan sedasi harian pasien.

Hasil dari wawancara terakhir Oktober 2015, dari 33 perawat ditemukan 15 perawat yang tidak mengetahui tentang penerapan VAP bundle sehingga masih ditemukannya infeksi nasokomial pneumonia yang disebabkan oleh ventilasi mekanik. Berdasarkan uraian diatas peneliti tertarik untuk meneliti "Adakah hubungan Tingkat Pengetahuan Perawat dengan Penerapan VAP Bundle Di ICU RSUP Dr. M. Djamil Padang

\section{METODE PENELITIAN}

Desain penelitian adalah studi analitik dengan pendekatan potong lintang (cross sectional). Penelitian ini bertujuan untuk mengetahui hubungan antara tingkat pengetahuan dengan penerapan VAP Bundle. Pada penelitian ini yang menjadi populasi adalah seluruh perawat yang kontak langsung dengan pasien diruang ICU RSUP Dr. M. Djamil Padang dengan jumlah adalah 29 perawat. Karakteristik responden menunjukkan bahwa hampir seluruh $(90 \%)$ responden berjenis kelamin perempuan, tingkat pendidikan menunjukkan bahwa lebih dari separuh (70\%) responden menyelesaikan S1 Keperawatan, lama bekerja menunjukkan bahwa hampir separuh $(43,3 \%)$ sudah bekerja lebih dari 10 tahun, lebih dari separuh $(53,3 \%)$ responden belum pernah mengikuti pelatihan ICU dan status kerja menunjukkan bahwa hampir seluruh (93,3\%) tenaga kesehatan adalah PNS diruangan ICU Dr. M. Djamil Padang.

Variabel pengetahuan diukur menggunakan kuesioner dan variable penerapan VAP Bundel diukur melalui observasi sesuai dengan poin-poin pada Bundle checklist. VAP bundle yang dinilai meliputi: meninggikan bagian kepala $30^{\circ}$ $45^{0}$ melakukan tindakan untuk DVT prophlaxis (tidak dikerjakan jika ada kontra indikasi seperti preexisting koagulasi atau defek trombosit, trombositopeni atau pendarahan abnormal, lesi ulseratif, lesi susunan saraf pusat), melakukan ulkus peptikum prophylaxis, pengurangan sedasi harian dan melakukan perawatan mulut. Analisis data dilakukan menggunakan statistic deskriptif dan chisquared test.

\section{HASIL PENELITIAN}

Data pada Tabel 1 menunjukkan bahwa lebih dari separuh $(60 \%)$ responden memiliki tingkat pengetahuan yang tinggi tentang Penerapan VAP Bundle di ruangan ICU RSUP Dr. M. Djamil Padang. Selanjutnya, Tabel 2 menunjukkan bahwa hampir seluruh $(93,3 \%)$ responden sesuai dalam melakukan penerapan VAP Bundle di ruangan ICU RSUP Dr. M. Djamil Padang.

Tabel 1.

Tingkat Pengetahuan Tenaga Kesehatan tentang Penerapan VAP Bundle.

\begin{tabular}{lcc}
\hline $\begin{array}{c}\text { Tingkat } \\
\text { Pengetahuan }\end{array}$ & f & \% \\
\hline Tinggi & 18 & 60 \\
Cukup & 12 & 40 \\
\hline
\end{tabular}

Tabel 2.

Tingkat Penerapan VAP Bundle oleh Tenaga Kesehatan.

\begin{tabular}{lcc}
\hline $\begin{array}{c}\text { Penerapan } \boldsymbol{V A P} \\
\text { Bundle }\end{array}$ & $\boldsymbol{f}$ & $\boldsymbol{\%}$ \\
\hline Sesuai & 28 & 93,3 \\
Tidak Sesuai & 2 & 6,7 \\
\hline
\end{tabular}

Berdasarkan tabel 3 menunjukkan bahwa dari 18 responden yang mempunyai pengetahuan tinggi terdapat $94,4 \%$ yang memiliki kategori sesuai dalam penerapan VAP Bundle, sedangkan dari 12 orang responden yang memiliki pengetahuan cukup terdapat $8,3 \%$ yang tidak sesuai dalam penerapan VAP Bundle. Dari hasil uji analisis chi-square diperoleh $\mathrm{p}$ value $=$ 1,000 yang berarti tidak terdapat hubungan yang bermakna antara tingkat pengetahuan tenaga kesehatan dengan penerapan VAP 
Bundle di ruangan ICU RSUP Dr. M. Djamil Padang.

Tabel 3.

Hubungan Tingkat Pengetahuan Tenaga Kesehatan dengan Penerapan VAP Bundle.

\begin{tabular}{|c|c|c|c|c|c|c|c|}
\hline \multirow{3}{*}{$\begin{array}{c}\text { Tingkat } \\
\text { pengetahuan }\end{array}$} & \multicolumn{4}{|c|}{ Penerapan VAP Bundle } & \multirow{2}{*}{\multicolumn{2}{|c|}{ Total }} & \multirow{3}{*}{ p value } \\
\hline & \multicolumn{2}{|c|}{ Sesuai } & \multicolumn{2}{|c|}{ Tidak Sesuai } & & & \\
\hline & f & $\%$ & $f$ & $\%$ & f & $\%$ & \\
\hline Tinggi & 17 & 94,4 & 1 & 5,6 & 18 & 100 & 1,000 \\
\hline Cukup & 11 & 100 & 1 & 8,3 & 12 & 100 & \\
\hline
\end{tabular}

\section{PEMBAHASAN}

Hasil penelitian dari tabel 1 didapatkan hasil $60 \%$ responden memiliki tingkat pengetahuan yang tinggi, sebanyak $40 \%$ memiliki tingkat pengetahuan yang cukup. Hasil penelitian ini tentang tingkat pengetahuan jauh lebih baik dibandingkan dengan penelitian Jansson, Kokko, Ylipalosaari, Syrjala dan Kyngas (2013) dimana didapatkan rendahnya pengetahuan perawat tentang pedoman berbasis bukti untuk pencegahan VAP sebayak 59.9\%.

Dalam penelitan ini lebih dari setengah tenaga kesehatan memiliki tingkat pengetahuan kategori tinggi, ini disebabkan lebih dari separuh responden (70\%) sudah menyelesaikan pendidikan S1 Keperawatan dan lama bekerja 79,9\% lebih dari 5 tahun bekerja di ruangan ICU RSUP Dr. M. Djamil Padang. Dalam Jansson, Kokko, Ylipalosaari, Syrjala dan Kyngas (2013) menyatakan bahwa pengalaman professional menunjukan adanya hubungan terhadap pengetahuan yang tinggi sehingga adanya keinginan untuk meningkatkan pelatihan atau pendidikan serta strategi dan implementasi yang efektif. Pernyataan ini didukung oleh Koentjaraninggrat (2003) Kemahiran dalam penyerapan pengetahuan akan meningkat sesuai dengan meningkatnya pendidikan seseorang dan berhubungan erat dengan sikap terhadap pengetahuan yang diserapnya, hal ini akan terlihat dari perilaku perawat dalam melaksanakan asuhan keperawatan dan semakin tinggi pengetahuan perawat terhadap tindakan perawatan maka semakin dilaksanakannya tindakan keperawatan tersebut

Berdasarkan pada pengisian kuesioner, di tingkat pengetahuan pada 30 responden didapatkan bahwa lebih dari separuh $60 \%$ responden tidak mengetahui jalur intubasi nasotrakeal. Selama peneliti melakukan mengobsevasi ditempat peneliti tidak seorangpun ditemukan pasien di intubasi melalui nasotrakeal, karena tidak adanya indikasi untuk melakukan intubasi nasotrakeal. Kebiasaan ini dapat mempengaruhi ketidaktahuan perawat tentang intubasi nasotrakeal.

Sebanyak $30 \%$ responden tidak mengetahui jadwal penggantian sirkuit ventilator, dan sirkuit tidak dapat diganti setiap 48 jam karena keterbatasan alat yang ada diruangan, terutama jika pasien penuh. Hal ini berbanding terbalik dengan Sherina (2010) dimana penggantian sirkuit setiap 48 jam mengurangi resiko terjadinya VAP.

Selanjutnya sebanyak 53,3\% responden tidak mengetahui jenis humidifier saluran nafas yang direkomendasikan, dan hasil observasi peneliti selama penelitian humidifier sudah tersambung langsung dengan ventilator tersebut dan alat humidifikasi yang direkomendasikan adalah HME (Heat and Moisture Exchanger).

Sebanyak $76,7 \%$ responden tidak mengetahui pengisapan lendir mana yang sangat direkomendasikan apakah itu secara terbuka (open suction) atau tertutup (close suction) karena responden mengerjakan sesuai dengan instruksi yang ada dan hasil diskusi peneliti dengan responden sebelum adanya close suction responden melakukan open suction dan menurut responden mungkin close suction adalah yang paling direkomendasikan.

Sebanyak $66,7 \%$ responden tidak mengetahui apakah tempat tidur standar atau elektrik dapat meningkatkan atau 
menurunkan resiko VAP. Penggunaan tempat tidur elektrik dan standar tidak mempengaruhi resiko terjadinya VAP.Untuk pencegahan VAP yang lebih penting adalah pengaturan posisi pasien elevasi tempat tidur $30^{\circ}-45^{\circ}$.

Sebanyak $66,7 \%$ responden tidak mengetahui apa yang perlu dilakukan untuk meningkatkan tingkat mobilitas pasien dengan ventilasi mekanik, yang mana seharusnya pasien harus latihan rentang gerak pertiga jam tapi selama peneliti melakukan observasi tidak ditemukan latihan rentang gerak dan hasil diskusi dengan responden hal terebut tidak terbiasa dilakukan karena kekurangan tenaga. Hal ini berbanding terbalik dengan Sherina (2010) latihan rentang gerak sangat bermanfaat, aktivitas otot menstimulus pernfasan dan dapat mencegah kontraktur dan statis vena.

Hasil penelitian dari tabel 2 didapatkan hasil lebih dari separuh 93,3\% reponden sesuai melakukan penerapan VAP Bundle dan 6,7\% responden tidak sesuai melakukan penerapan VAP Bundle. Hal ini sejalan dengan penelitian Jansson, Kokko, Ylipalosaari, Syrjala dan Kyngas (2013) dilaporkan secara keseluruhan kepatuhan perawat tehadap VAP bundle sebanyak $84.0 \%$ dan didukung oleh penelitian Mohamed (2014) bahwa adanya perbedaan antara pre dan post intervensi setelah pengaplikasian VAP bundle, didapatkan adanya peningkatan hasil yang signifikan dari pasien trauma dimana setelah dilakukan VAP bundle mencerminkan adanya penurunan angka kematian.

Dalam penelitian ini didapatkan di Bundle Checklist sudah $100 \%$ responden sudah mengerjakan elevasi tempat tidur $30^{0}-45^{\circ}$, sebanyak $100 \%$ sudah melakukan pengurangan sedasi harian, dan persiapan untuk ekstubasi sesuai indikasi tetapi pada saat penelitian ditemukan 3 orang responden yang tidak melakukan pengurangan sedasi harian dengan alasan hemodinamik pasien tidak stabil. Sebanyak $100 \%$ responden sudah memberikan ulkus peptikum prophilaxis, dan sebanyak $93,3 \%$ reponden mengerjakan oral care dengan chlorhexidine.

Selama penelitian DVT Prophylaxis tidak dilakukan responden tetapi dianggap melakukan, karena banyaknya kontraindikasi terhadap pasien seperti preexisting koagulasi atau defek trombosit, trombositopeni atau pendarahan abnormal, lesi ulseratif, lesi susunan saraf pusat.

Dengan penerapan VAP bundle, banyak manfaat yang bisa didapat pasien Gallagher (2012) mengatakan dari bahwa implementasi VAP Bundle mengurangi lama hari rawat, hari penggunaan ventilator dan angka kejadian VAP.

Berdasarkan tabel 4 menunjukkan bahwa dari 18 responden yang mempunyai pengetahuan tinggi terdapat $94,4 \%$ yang memiliki kategori sesuai dalam penerapan VAP Bundle, sedangkan dari 12 orang responden yang memiliki pengetahuan cukup terdapat $8,3 \%$ yang tidak sesuai dalam penerapan VAP Bundle.

Hasil uji analisis chi-square diperoleh $\mathrm{p}$ Value $=1,000$ yang berarti secara statistic tidak terdapat hubungan yang bermakna antara tingkat pengetahuan tenaga kesehatan dengan penerapan VAP Bundle di ruangan ICU RSUP Dr. M. Djamil Padang tahun 2015.

Penelitian ini juga didukung oleh Pogorzelska (2011) yang mengatakan bahwa semua intervensi yang ada dalam VAP Bundle jika dilakukan secara keseluruhan untuk mengurangi angka kejadian VAP.Untuk mengurangi kejadian VAP juga dibutuhkan suatu monitoring terhadap implementasi intervensi di tempat kerja.

Secara uji statistic meskipun tidak terdapat adanya hubungan signifikan antara pengetahuan dengan penerapan VAP Bundle, namun secara proporsi didapatkan bahwa penerapan VAP Bundle yang tidak sesuai lebih banyak pada perawat yang berpengetahuan cukup $(8,3 \%)$ dibandingkan dengan perawat yang berpengetahuan tinggi $(5,6 \%)$.

Masih ada responden yang tingkat pengetahuan cukup, tidak sesuai melakukan penerapan VAP Bundle, disebabkan karena pendidikan respoden 
D3 Keperawatan dan responden belum mengikuti pelatihan ICU. Data ini didukung oleh Gallagher (2012) mengatakan strategi implementasi yang aktif adalah dengan pelatihan staff dan pengingat klinis (Clinical Reminder), dengan adanya pelatihan staf akan dapat meningkatkan pengetahuan staff tentang penerapan VAP Bundle sehingga staff akan dapat menerapkan VAP Bundle yang sesuai.

Faktor lain yang lain yang mempengaruhi terhadap menerapkan VAP Bundle adalah sikap, motivasi, beban kerja. Berdasarkan hasil penelitian yang dilakukan oleh Wulandari (2015) tentang sikap caring perawat terhadap pelaksanaan oral hygiene di ruang intensive RSUD Dr. Moewardi Surakarta. Hasil penelitian menunjukkan bahwa ada hubunganantara sikap caring perawat terhadap pelaksanaan oral hygiene. Oral hygiene merupakan salah satu bagian dari penerapan VAP Bundle.

Menurut Agus (2009) Kurangnya motivasi perawat dalam penerapan VAP Bundle yang tidak kondusif dapat mempengaruhi perubahan perilaku kepedulian perawat terhadap penerapan VAP Bundle. Kapasitas pasien yang melebihi kemampuan kerja perawat dalam melaksanakan perawatan akan mempengaruhi terhadap penerapan VAP dimana tingkat kesibukan perawat, ataupun tidak seimbangnya beban kerja juga mempengaruhi penerapan VAP Bundle.

Gallagher (2012) juga menyatakan strategi implementasi yang aktif adalah dengan pelatihan staff dan pengingat klinis (Clinical Reminder) sehingga akan meningkatkan penerimaan penelitian ini memberikan bukti yang cukup untuk mendukung implementasi VAP Bundle.

Hasil penelitian tentang pengetahuan jauh berbeda dengan hasil survey pendahuluan, perawat tidak tahu tentang adanya VAP Bundle, tapi mengetahui poinpoin yang terdapat pada VAP bundle. Adapun Kelebihannya yang didapat jika secara simultan mengetahui ataupun menerapkan keseluruhan poin-poin VAP Bundle hasil yang didapat pada pasien akan lebih baik jika dibandingkan dengan hanya menerapkan setiap poinnya secara tidak simultan.

\section{KESIMPULAN}

Tingkat pengetahuan tenaga kesehatan yang mayoritas baik di ICU RS Dr M Djamil Padang telah diikuti dengan penerapan VAP Bundle yang baik pula. Disarankan kepada pihak rumah sakit dapat memberikan variasi pelatihan lanjut atau khusus tentang keperawatan kritis termasuk desiminasi jurnal terutama tindakan ventilasi mekanik sehingga perawat dapat menambah wawasan pengetahuan ilmu-ilmu terbaru sehingga dapat menambah kualitas perawat. Bagi manajemen ruangan agar dapat menetapkan VAP Bundle sebagai prosedur operasional standar sehingga diterapkan secara konsisten oleh para perawat dalam mencegahnya VAP.

\section{DAFTAR PUSTAKA}

Bestable, S. (2002). Perawat sebagai Pendidik: Prinsip-Prinsip Pengajaran Dan Pembelajaran. Jakarta: EGC.

Cook, D., Fuller, H., \& Guyatt, G. (1994). Risk Factor for Gastrointestinal bleeding in critically iil patients. $N$ Engl J Med , 3771-381.

Dewi, S. A., \& dkk. (2014). Keperawatan Intensif Dasar, modul pelatihan, Kelompok Kerja Keperawatan Iintensif PP HIPERCCI. Bogor: In Media.

Fartoukh, M., Maitre, B., Honore, S., Cerf, C., Zahar, J., Buisson, B., et, al. (2003). Diagnosing Pneumonia During Mechanical ventiator. Am J Respir Crit Care med , 173-179.

Gallagher, D. J. (2012). Implementation of Ventilator-Associated Pneumonia Guideline (Bundle). The journal for Nurse Practitioner-JNP, 8(5).

Hudak, R. C., \& Gallo, R. B. (1995). Keperawatan Kritis, Pendekatan Holistik (Critical Care Nursing.A Holistic Approach). Jakarta: Penerbit Buku Kedokteran EGC.

Jansson, M., Kokko, T. A., Ylipalosaari, P., Syarjala, H., \& Kyngas, H. (2013). 
Critical care nurses' knowledge of, adherence to and barriers toward evidence-based guidelines for the prevention of ventilator-associated pneumonia-A survey study. Intensive and Critical Care Nursing, 29, 216227.

Koentjaraninggrat. (1997). Metode-metode Penelitian Masyarakat. Jakarta: Gramedia.

Marya, D., \& Andrew, S. F. (2010). Ventilator-Associated Pneumonia: The Clinical Pulmonary Infection Score as Surrogate For Diagnostic and Outcome. Clinical Infection diseases Oxford Journals, 131-135.

Meliono, I. (2007). MPKT modul 1. Jakarta: Lembang Penerbitan FEUI.

Mohamed, K. A. (2014). Compliance with VAP bundlle implementation and its effectiveness on surgical and medical sub-population in adult ICU. Egyptian Journal of Chest Disease and Tuberculosis, 63, 9-14.

Munro, R.-B. N., \& Ruggiero, R.-B. M. (2014). Ventilator-Associated Pneumonia Rescontruction For Best Care. AACN Advanced Critical Care, 25, 163-175.

Musliha, S. (2010). Keperawatan Gawat Darurat. Yogyakarta: Nuha Medika.

Notoadmojo, S. (2007). Promosi Kesehatan dan Ilmu Perilaku. Jakarta : Rineka Cipta.

Notoatmodjo, P. (2012). Metodologi Penelitian Kesehatan. Jakarta: Rineka Cipta.

Notoatmodjo, S. (2012). Metode Penelitian Kesehatan, edisi revisi. Jakarta: Rineka Cipta.

Saanin, S. (2006). Infeksi Sistemik pada Pasien Bedah Syaraf yang dirawat Intensif . Padang.

Setiadi, T. E., \& Soemantri, A. (2009). Acute Respiratory Distress Syndrome (ARDS) Patofisiologi, Dinamika Kardiovascular dan lung Recruitment Therapy. Semarang: Pelita Insani Semarang.

Sherina, \& RSCM, T. I. (2010). Gagal nafas dab Ventilasi Mekanik,Modul Pelatihan ICU RSCM. Jakarta.
Sundana, k. (2014). Ventilator Pendekatan Praktis Di Unit Perawatan Kritis. Bandung: CICU Bandung.

Terry, C. L., \& Weaver, A. (2013). Keperawatan Kritis. Yogyakarta: Rapha.

Vincent, J., Abraham, E., Kochaneck, P., Moore, F., \& Fink, M. (2011). Textbook of Critical Care Sixth Edition. Elsevier Sunders, 328-479. 